\title{
PRODUÇÃO DE MATERIAL DIGITAL DE VIDEO PARA DIVULGAÇÃO DO PROGRAMA DESPERTANDO VOCAÇÕES
}

\author{
Apresentação: Relato de Experiência \\ Autor Principal: Eduarda Nascimento da Silva Orientador: Erick Viana da Silva
}

\section{Introdução}

O marketing digital desperta interesse dos jovens na sociedade atual pelo fato de estar diretamente associado ao universo das redes sociais. "A familiaridade dos jovens e das crianças com as novas mídias e o seu crescente interesse pela produção colaborativa de conteúdos são decorrentes da popularização dos computadores e da internet e agora potencializados pela presença dos celulares entre eles." (EHRENBERG \& GALINDO, 2010). Simples vídeos ganham espaço em redes sociais e se mutiplicam exponencialmente à medida que seus protagonistas se tornam personalidades do público que interage com o universo virtual. O Programa Internacional Despertando Vocações (PDV) iniciou no ano de 2017 a implementação de um Grupo de Trabalho com o intuíto de sistematizar a divulgação das ações do PDV e melhorar a comunicação interna e externa. Para (KOTLER, 1999 p.30) o marketing é como um processo social "por meio do qual pessoas e grupos de pessoas obtêm aquilo de que necessitam e que desejam com a criação, oferta e livre negociação de produtos e serviços de valor com outros". O objetivo desse relato de experiência é narrar a trajetória de implementação do grupo de marketing e mídias virtuais do Programa Despertando Vocações, especificamente a criação de mídias virtuais (áudio, vídeo e textos) para divulgação nas redes sociais.

\section{Relato de Experiência}

A oportunidade de trabalhar com aplicativos editores de vídeo proporciona ao discente uma experiência rica. A produção dos vídeos é dividida em filmagem, orientação, iluminação e equipamentos, o básico necessário é o conteúdo e a interação do autor do vídeo com a câmera. Após a filmagem entra em cena a edição, utilizando alguns sofwares para o aprimoramento de 
imagem e som, incluindo a inserção de caracteres e de alguns áudios, tornando o vídeo mais atrativo. Esse relato de experiência faz parte de um grupo de marketing e mídias sócias no qual há estudantes de todas as áreas do PDV: Licenciaturas, Ciências Agrárias, Gestão e Tecnologias) das Instituições: Instituto Federal(IF) de Pernambuco - Campus Recife,Vitória; IF Sertão-PE Campus Salgueiro; IF de Rondônia - Campus JiParaná; Universidade Federal Rural de PE - UAST e UAG; IF da Paraíba; IF do Piauí - Campus Terezina, IF do Rio Grande do Norte - Campus Natal central e FACHUSC Salgueiro, Universidad Nacional de La Plata (Argentina) e INACAP (Chile). No primeiro momento foi necessário uma pesquisa por aplicativos que de forma gratuita fossem utilizados no celular e notebook para melhoramento desses vídeos, há membros com experiência com YouTube do próprio Programa aptos a darem capacitação para novos estudantes, os editores VivaVideo e FilmaraGo foram usados na edição do vídeos. A partir daí foi iniciada uma produção sistemática de vídeos sobre diversas temáticas com a conotação de informalidade, no formato de selfies vídeos e postados no instagram e facebook para logo após serem disseminados por toda rede de contatos dos participantes. A experiência inicial rendeu em menos de $24 \mathrm{~h}$ aproximadamente 2500 visualizações nas primeiras postagens. Uma outra característica positiva da experiência é a utilização no ambiente acadêmico de plataformas vistuais e estratégias que são utilizadas por organizações atualizadas às novas tecnologias com trabalhos colaborativos com atores em diversas partes do mundo de forma síncrona ou assíncrona.

\section{Considerações}

Com o avanço tecnológico as atividades profissionais, em geral, estão cada vez mais virtualizadas ou em processo de virtualização, se não em todo, mas ao menos em partes. A experiência com plataformas virtuais e utilização da comunicação com seu público através de vídeos trás ao estudante uma oportunidade de investir em uma perspectiva de utilização dessas ferramentas cujo aprendizado se deu de forma, não curricular, como uma ampliação do universo de possibilidades de atuação, não convencional, da prática profissional utilizando novas Tecnologias de Informação e Comunicação.

\section{Referências}

EHRENBERG, Karla Caldas; GALINDO. Os jovens consumidores conectados e o móbile marketing não-linear . Congresso Panamericano de Educação, Brasília, 2010. Disponível na URL: http://www.ipea.gov.br/panam/pdf/GT2_Art5_Karla.pdf e acessado em 14/10/2017.

KOTLER, P. \& ARMSTRONG, G. Princípios de Marketing. 7a. ed. Rio de Janeiro: LTC,1999.

VivaVideo: Free Video Editor para Android https://filmora.wondershare.com.br/filmorago-videoediting-app/ 